The study of relationship between parenting styles and personality dimensions in sample of college students

\author{
Mohammad Ebrahim Maddahi ${ }^{{ }^{1}}$, Nasirudin Javidi $^{2}$, Mona Samadzadeh $^{3}$ and Maryam Amini ${ }^{4}$ \\ ${ }^{1}$ Department of Psychology, Shahed University, Tehran, Iran \\ ${ }^{2}$ University of Science \& Culture, Department of Psychology, Family Therapy, Tehran, Iran \\ ${ }^{3}$ University of Science \& Culture, Department of Psychology, Family Therapy, Tehran, Iran \\ ${ }^{4}$ Shahed University, Department of Psychology, Tehran, Iran \\ memadahi@yahoo.com
}

\begin{abstract}
The present study aims to explore the relationship between parenting styles (including authoritative, authoritarian, permissiveness and neglectful) and personality dimensions (including five factors as extroversion, agreeableness, conscientiousness, neuroticism and openness to experiences). For this purpose, 272 students from national university, Islamic Azad University and Payam Nour University of Yazd pre-province were selected at random and responded to Parenting Styles Questionnaire (Naghashian, 1979) and Five-Factor Personality Factors Questionnaire (Costa and McCrae). The findings show that among all the components of personality, there is a direct and significant relationship only between openness personality trait and authoritative parenting style; that is to say, authoritative parenting style is correlated with developing openness trait components (including, having desire for curiosity, imagination, aesthetics, wisdom, enlightenment and humanism).
\end{abstract}

Keywords: Parenting style, Personality traits, Student

Introduction
Family is the main pillar and the first of child's personality development. The quality of the relationship between parents and children is considered as the determining factor of adjustment and their interaction to each other as well as psychological and emotional atmospheres dominant on the family form the behavioral and personality characteristics of children (Sarmast, 2006). The issue of socialization has been practiced on human beings by various sources and each one makes up the cultural and social personality of the socialized one. Family played the main role in most societies, including Iran amongst this and it has the most influence in the process of human's socialization and acculturation. Various studies have been performed indicating that one of the most effective factors on the development and formation of adolescent's personality is their parent's parenting practices (Belsky \& Barrendz, 2002; Prinzieh et al., 2004). Parenting styles are patterns for children's training that is formed by the normative interaction of parents and how they response to children's behavior (Kaplan et al., 2002; cited in Desjardins, 2009). In addition, various studies showed the relationship between five personality traits including learning styles (Komarajou et al., 2011), academic achievement (Atashrouz et al., 2008) and mental health (Outani et al., 2009) which indicate the importance of addressing this area.

Psychologists are different from each other in terms of the meaning of personality. Most of them agree that the term personality is a relatively stable trait, tendencies or features that perpetuate individual's behavior to some extent; or more specialized, personality is made up of traits and tendencies whichis led to individual differences in behavior, behavior stability over time and behavior continuity in various situations (Feist \& Feist, 2002).

CIndian Society for Education and Environment (iSee)
McCrae and Costa (1992) and McCrae and John (1992) described personality along five dimensions or five main factors, including openness to experience, conscientiousness, extroversion, agreeableness and neuroticism. Openness to experience is the desire for curiosity, imagination, aesthetics, wisdom, enlightenment and humanism (John, 1989; McCrae \& John, 1992; McCrae \& Costa, 1992). Conscientiousness is the desire for organization, discipline, autonomy, efficiency, reliability, continence, progressiveness, logic-focused and reflection (John, 1989; McCrae \& John, 1992, Watson \& Clarck, 1997). Agreeableness refers the desire for amnesty, kindness, benevolence, confidence, empathy, obedience and sacrifice (John, 1989; McCrae \& John, 1992). Neuroticism is the desire to experience anxiety, stress, self-consuming, hostility, impulsiveness, shyness, irrational thinking, depression and low self-esteem (John, 1989; McCrae \& John, 1992; McCrae \& Costa, 1992).

Different patterns are presented by researchers in the study of parenting styles. McCobay and Martin's parenting style (1983, Seligman \& Rouznahan, 2003), which is the evolved form of parenting styles of Bamarynd, is one of the most commonly used patterns in the field of parenting practices. Bamarynd (1971) explained two independent dimensions in education which is able to predict children's behavior. The first dimension, i.e. responsiveness, is the amount of nutrition, warmth, emotional expression and positive reinforcement associated with children's opinions. The second dimension, i.e. demandingness, refers to control application method, level of demand and expectations. Based on these two dimensions, there are four types of parenting styles: authoritative (high on both dimensions), authoritarian (high on demandingness and low on 
responsiveness), permissive (low on demandingness and high at responsiveness) and neglectful (both in low).

There are different combinations of two dimensions of parenting styles, i.e. affection and control in each dimension. Parents who apply authoritarian educational pattern are cold and unkind towards their children and at the same time have a high control on their children along with punishments and lots of restrictions. Not only are authoritative parents warm, kind and receptive, they are also restrictive, but they explain the cause of these restrictions with logic to their children. Parents express lots of kindness to their children in permissive parenting style, but they have low control on their behaviors, and there are both low kindness and control in the relationship between parents and children in neglectful parenting style. Each of these styles has different effects on children; children with authoritative parenting style have better social-emotional development and academic performance (Biougental \& Grousis, 2006; Desjardines, et al., 2009) and show higher organized and rational orientation (Hill, 1995), and adolescents with authoritative parents consume less smoke and marijuana and drink less alcohol (Jackson et al., 1998; Krimirz et al., 2003) and have better psychological development and more scientific competence as well as less neglectful behavior and physical symptoms (Stinburgh et al., 1994). While permissive parents have no control on their children and these children show the least amount of self-confidence, curiosity and self-control in each group and have difficulty in controlling impulses, recognizing values and antivalues (Bamarind, 1971; Burn Stein, 2002). Authoritarian parents often humiliate their children and no explanation they give about the punishment exerted, for performing strong disciple causes impairment children's processing massages and parent talk and they are living in constant fear (Hartoup \& Lawrence, 1993; Barber, 2000). Therefore, the present study examines the relationship between parenting styles and personality dimensions.

Research method

This research is the type of non-experimental and correlation study (Sharifi \& Sharifi, 2004). Correction studies are applied for two purposes: the first one is correlation study of multi-variables and the other is to predict a variable by another variable or other variables. The general scheme of this study is descriptive-sectional. There are two types of variables in this study: independent variables (predictive) parenting styles and dependent variable (criterion) personality types. Research methodology used in this study is based on the assumptions of correlation studies. In this study, the relationship between parenting styles variables and related factors (4 factors) as predictive variables (independent) with personality types variable as dependent variable (criterion)are assessed and regression and causal relationships between them are regulated.

\section{Research samples}

In this study, the number of subjects under study is obtained from the Koukranformulae $\mathrm{n}=\frac{\sigma^{2} \cdot \mathrm{z}^{2}}{\mathrm{~d}^{2}}$. Due to the fact that the community approximate mean $(a)$ in NEO questionnaire is 34 and the difference between actual mean of community and equivalent average of one standard deviation is supposed 4.02 (Ahadi, 2007), thus, the required minimum sample size is calculated 275 ones. The stages of calculation are as follows:

$$
\mathrm{n}=\frac{34^{2} \cdot 1 / 96^{2}}{4 / 02^{2}}=274 / 8 \cong 275
$$

Based on the experiences and performed studies, it is predicted that this required minimum sample is not met; therefore, sample size was increased to 300 people. These people were selected from the student community of National Universities, Islamic Azad University, Payam Nour University of Yazd pre-province in simple random method and finally 272 subjects returned completed questionnaires on which statistical analysis was performed on these data.

\section{Research tools}

Parenting style questionnaire: To assess parent's parenting style, a questionnaire composed of 77 questions being developed by two dimensions affection (coldness, warmth) and control (control-freedom) by Naghashian was used. Naghashian reported the reliability coefficient of this test 0.87 with division method, Yaghoubi (1993) reported the reliability coefficient 0.92 and 0.82 with division and Cronbach's alpha methods, respectively, and Tahmotan(1998) reported the controlfreedom dimension 0.74 through Cronbach's alpha and 0.89 for coldness-warmth dimension relationships and 0.85 for the whole scale. In his initial studies, Naghashianobtained the test validity through content validity. Yaghoubkhani Ghiasvandi (1993) applied principal components analysis using varimax rotation to study the effects of factorial validity of questions and in overall showed that factor analysis confirmed the factorial validity of questions and corroborated the opinion of the constructor of the questionnaire indicating that the mentioned tool assesses two given dimensions. It is worth mentioning that evidences related to validity and reliability of this scale have been reported favorable through various researchers, including Tahmotan (1998), Razavieh and Khoshbakht (2005).

NEO-FFI-60 Five Personality Factor Questionnaire: This is a self-report questionnaire composed of 60 questions based on Likert scale ranged from $1=$ totally agree to $5=$ totally disagree in which each 12 questions measure big five personality factors (extraversion, agreeableness, conscientiousness, neuroticism and openness). Regarding NEO-FFI authenticity, the results indicate that NEO-FFI subscales have good inner acceptance. For 
example, in the study conducted by Costa and McCrae (1992), Cronbach's alpha coefficient was reported between 0.68 for agreeableness and 0.86 to neuroticism. Helden (1999) also reported the Cronbach's alpha of these five factors in the range of 0.76 for openness to 0.87 for neuroticism. The results of the study performed by Moradian and Nazlak (1995) indicate that Cronbach's alpha for neuroticism, extroversion, openness, agreeableness and conscientiousness are 0.84, 0.75, $0.74,0.75$ and 0.83 , respectively. NEO-FFI questionnaire was standardized by GarousiFarshi (1998) in Iran. The validity of this questionnaire using retest method for 208 students over three months is obtained $0.83,0.75,0.80$, 0.79 and 0.79 , respectively for N,E,O,A and C factors. Also, in the study conducted by Mollazadeh (2002, cited in FathiAshtiani and Dastani, 2009), the retest coefficient over 37 days for 76 people of Shahed children was reported as $0.83,0.78,0.73,0.79$ and 0.85 , for neuroticism, extroversion, openness, agreeableness and conscientiousness, respectively.

Also, Cronbach's alpha was obtained for neuroticism, 0.86; extroversion, 0.83 ; openness, 0.74 ; agreeableness, 0.76 ; conscientiousness, 0.87 and the total alpha, 0.83 . Regarding the concurrent validity of this questionnaire and Physical Symptom Questionnaire of Mayers-Bricks, California Revised Questionnaire, Glifourd and Zuckerman Temperament Study, list of traits and interpersonal trait scale, a high relationship have been reported (Mollazadeh, 2002; FathiAshtiani \& Dastani, 2009).

\section{Finding}

In Tables 1 and 2, descriptive indicators of participant's frequency distribution in terms of age distinction and descriptive indicators of participant's scores in parenting style and personality factors have been shown. In Table 3, the results of multiple regression analysis to predict the openness component based on parenting styles have been shown. As can be seen, R2(0.035) means that $3.5 \%$ of openness variance of personality dimensions variable are indicated by parenting styles variables. In other words, $3.5 \%$ of observed distribution in openness of personality dimensions is justified by these four variables. Also, the amount of observed R2 (0.187) indicate that regression model can be poorly used for prediction. Nonetheless, the ration of calculated $F(2.426)$ has an acceptable level $(0.048<0.05)$. Therefore, it can be concluded that there is a significant correlation between 4 variables of participant's parenting styles with openness factor.

Information mentioned in the table show that coefficient (beta column) related to authoritative, authoritarian and neglectful parenting styles variables is negative, but the beta coefficient related to permissive parenting style variable is positive, though by referring to the $t$ statistic and significance level, it can be judged that among the above-mentioned variables, only authoritative parenting style $(\beta=-2.568, \quad \mathrm{P}<0.05)$ has a significant correlation with openness which can be a predictor for openness.

According to the correlation direction of this variable, it can be concluded that by increasing one unit of this variable, openness out of personality dimension component will be increased 0.0109 units. Also, there is negative significant relationship between authoritative parenting style and openness component.

The Table 4 shows that there is an inverse and significant relationship between authoritative parenting style and neuroticism parenting style. Also, it is shown that there is a direct and significant relationship between authoritarian parenting style and neuroticism parenting style.

Table1. Descriptive indicators of participant's frequency distribution in terms of age distinction

\begin{tabular}{|c|c|c|c|c|c|c|c|c|}
\hline Indicators Variables & Number & mean & median & index & Standard deviation & minimum & maximum & range \\
\hline Age & 272 & 23.10 & 22 & 22 & 3.448 & 17 & 35 & 18 \\
\hline
\end{tabular}

Table 2. Descriptive indicators of participant's scores in parenting style and personality factors (N-214)

\begin{tabular}{|c|c|c|c|c|c|c|c|c|c|}
\hline $\begin{array}{l}\text { Indicators } \\
\text { Variables }\end{array}$ & Mean & $\begin{array}{l}\text { Mean } \\
\text { standard } \\
\text { error }\end{array}$ & Median & $\begin{array}{l}\text { Standard } \\
\text { deviation }\end{array}$ & minimum & maximum & Range & Strain & Deviation \\
\hline $\begin{array}{l}\text { Authoritative } \\
\text { parenting style }\end{array}$ & 21.49 & 0.263 & 21 & 4.341 & 14 & 34 & 20 & 0.951 & 0.440 \\
\hline $\begin{array}{l}\text { Authoritarian } \\
\text { parenting style }\end{array}$ & 18.63 & 0.239 & 19 & 5.432 & 6 & 38 & 32 & 0.079 & 0.332 \\
\hline $\begin{array}{c}\text { Permissive parenting } \\
\text { style }\end{array}$ & 17.50 & 0.364 & 17 & 6.000 & 8 & 34 & 26 & 0.382 & -0.405 \\
\hline $\begin{array}{c}\text { Neglectful parenting } \\
\text { style }\end{array}$ & 17.61 & 0.346 & 18 & 5.701 & 6 & 45 & 39 & -0.107 & -0.027 \\
\hline Neuroticism (N) & 27.92 & 0.474 & 26.50 & 7.818 & 6 & 45 & 39 & -0.107 & -0.027 \\
\hline Extroversion (E) & 28.76 & 0.578 & 28.50 & 7.879 & 5 & 46 & 41 & -0.178 & -0.227 \\
\hline Openness (O) & 29.44 & 0.471 & 26 & 7.760 & 7 & 45 & 38 & -0.066 & -0.048 \\
\hline Agreeableness (A) & 29.63 & 0.476 & 26 & 7.852 & 7 & 45 & 38 & -0.146 & -0.038 \\
\hline Conscientiousness $(\mathrm{C})$ & 29.72 & 0.574 & 26 & 7.828 & 4 & 46 & 42 & -0.153 & -0.038 \\
\hline
\end{tabular}


Table 3. Multiple regression analysis to predict the openness component based on parenting styles

\begin{tabular}{|c|c|c|c|c|}
\hline \multirow{2}{*}{ Predictors } & \multicolumn{3}{|c|}{ Openness } & Significance level \\
\cline { 2 - 5 } & Non-standardized coefficient & $\begin{array}{c}\text { Standardized coefficient } \\
\text { (beta) }\end{array}$ & $\mathrm{t}$ & 0.011 \\
\hline Authoritative parenting style & -0.280 & -0.109 & 2.568 & 0.691 \\
\hline Authoritarian parenting style & -0.034 & -0.024 & -1.398 & 0.951 \\
\hline Permissive parenting style & 0.154 & 0.119 & 0.857 & 0.789 \\
\hline Neglectful parenting style & -0.022 & -0.016 & -0.267 & \\
\hline
\end{tabular}

$\mathrm{R}=0.187, \mathrm{R}^{2}=-0.035$, Adjusted $\mathrm{R}^{2}=0.021, \mathrm{~F}=2.426$

Table 4. Multiple regression analysis to predict the neuroticism component based on parenting styles

\begin{tabular}{|c|c|c|c|c|}
\hline \multirow{2}{*}{ Predictors } & \multicolumn{3}{|c|}{ Neuroticism } & Significance level \\
\cline { 2 - 5 } & Non-standardized coefficient & Standardized coefficient (beta) & $\mathrm{t}$ & 0.091 \\
\hline $\begin{array}{c}\text { Authoritative parenting } \\
\text { style }\end{array}$ & -0.280 & -0.109 & -1.23 & 0.801 \\
\hline $\begin{array}{c}\text { Authoritarian parenting } \\
\text { style }\end{array}$ & -0.034 & -0.024 & 2.08 & 0.490 \\
\hline $\begin{array}{c}\text { Permissive parenting } \\
\text { style }\end{array}$ & 0.154 & 0.119 & 0.260 & 0.427 \\
\hline $\begin{array}{c}\text { Neglectul parenting } \\
\text { style }\end{array}$ & -0.022 & -0.016 & -0.330 & \\
\hline \multicolumn{2}{|c|}{$\mathrm{R}=0.128, \mathrm{R}^{2}=-0.052$, Adjusted $\mathrm{R}^{2}=0.022, \mathrm{~F}=2.316$} \\
\hline
\end{tabular}

\section{Results and discussion}

Regarding the research hypothesis, the results of statistical analysis showed that there is an inverse relationship between authoritarian parenting style and openness parenting style and there is a direct relationship between authoritative parenting style and openness parenting style. Also, there is an inverse and significant relationship between authoritative parenting style and neuroticism parenting style and it has been shown that there is a direct and significant relationship between authoritarian parenting style and neuroticism. In fact, the results of this study showed that parent's educational manners and styles are effective on the formation of children's personality traits. This finding is compatible with the other studies (Bamerind, 1971; Costa \& McCrae, 1992; Belsky \& Barndez, 2002; Burn Stein, 2002; Pernizieh et al., 2004; Biogetnal \& Grousis, 2006; Desjardins, 2009).

The methods parents apply on their children's training have major roles in providing their mental health. It is in a healthy relationship that children's needs can be identified and then tries to supply and satisfy them. As indicated, each of these methods has some effects on children's behavior, which the negative and destructive effects of permissive and authoritarian methods are more than others. Coopersmith (1976), (Sepehri, 2009) showed that in comparison to authoritarian parents, the parents who have permissive parenting style are more prone to train children who have a high amount of self-respect and authoritative parents give positive effects in their adolescent's lifestyle which cause them to consume less smoke and marijuana as well as drink less alcohol
(Jackson et al., 1998). Also, they have less physical symptoms (Stingurgh et al., 1994).

Children with authoritative education style have higher social-emotional development and better academic performance. The studies performed by Costa and McCrae (1992) showed that the communicative dimension (warmth and support) is in a high level in authoritative parenting style and the children who are trained under this pattern show more humanism. On the other hand, a set of social support, mutual relationships, receptivity, responsiveness and satisfaction towards children can be seen in authoritative parenting style which causes the development of these components within children (Bamarind, 1971). Also, Maddahi and Samadzadeh (2010) showed that three personality traits, namely agreeableness, extroversion and openness has a positive relationship with authoritarian and permissive parenting style and has a negative relationship with authoritative parenting style and conscientiousness personality trait has a positive relationship with authoritative and authoritarian parenting styles and a negative relationship with permissiveness parenting style. Therefore, it can be generally concluded that parent's parenting styles and the way they interact with their children can be effective on evolving children's personality traits and the parents who support authoritative parenting styles contribute to evolving positive characteristics such as agreeableness, extroversion and openness in their children. Therefore, it is recommended that training points be presented to parents according to the results obtained.

\section{References}

1. Baumrind D (1971) Current patterns of parental authority. Develop. Psychol. Monographs. 4, 1-1020.
CIndian Society for Education and Environment (iSee)
M.E.Maddahi et al. Indian J.Sci.Technol. 
2. Belsky J and Barends N (2002) Personality and parenting. In: Bornstein MH (Ed.), Handbook of Parenting (2nd ed). Bening \& Becoming a Parent. Mahwah, NJ: Erlbaum. 3, 415-438.

3. Bornstein M (2002) Handbook on parenting children and parenting.

4. Barber N (2000) Why parents matter. Websport CT: Bergin \& Garvery.

5. Costa PT and Mccrae RR (1992) Revised NED personality Inventory (NEO PI-R) and NEO five- factor Inventory (NEO-FFI) professional manual. O dessa, FL.

6. Desjardins J, Zelenski JM and Coplan RJ (2008) An investigation of maternal personality, Parenting styles and subjective well-being. Person. \& Individual Diff. 44,587-597.

7. Hartup W and Laurson B (1993) Conflict and context in peer relation. In C.Hart (Ed). Children on playgrounds: Research \& Perspectives \& Appl. Albany NY: SUNY Press. pp: 44-84.

8. Hill NE (1995) The relationship between family environment and parenting Style: A preliminary study of African American families. J. Black Psychol. 21, 408423.

9. Jackson C, Henriksen L and Foshee VA (1998) The authoritative parenting index: Predicting health risk behaviors among children and adolescents. Health Edu. \& Behavior. 25, 319-337.

10. John OP (1989) Towards a taxonomy of personality descriptions, In D. M. Buss, \& N Cantor (eds.), Personality psychology: recent trends and emerging directions. NY: Springer. pp: 261-271.

11. Komarraju M, Karau SJ, Schmeck $R$ and Avdic A (2011) The big five personality traits, learning styles, and academic achievement. Person. \& Individual Diff. 51(4), 472-477.

12. Kremers SP, Brug J, De Vries H and Engels Rc (2003) Parenting style and adolescent fruit consumption. Appetite. 41, 43-50.

13. McCrae RR and Costa JPT (1992) Validation of the five-factor model of personality across instruments and observers. J. Personality \& Soc. Psychol. 52, 81-90.

14. McCrae RR and John OP (1992) An introduction to the five-factor model and its application. Special issue: the five-factor model: issues an application. J. Person. 60, 175-215.

15. Otani K, Suzuki A, Oshino Sh, Ishii $G$ and Matsumoto $Y$ (2008) Effects of the "affectionless control" parenting style on personality traits in healthy subjects. Psychiatry Res. 165(1-2), 181-186.

16. Prinzie $P$, Onghena $P$, Hellinckx $W$, Grietens $H$, Ghesqviere P and Colpin H (2004) Parent and child personality charaeteristics as predicters of negative discipline and externalizing problem behaviour in children. Eur. J. Person. 18, 73-102.

17. Steinberg I, Lamborn SD, Darling N, Mounts NS and Dornbusch SM (1994) Over-time changes in adjustment and competence among adolescents from $\begin{array}{lll}\text { Vol. } 5 & \text { No. } 9 & \text { (Sep. 2012) ISSN: 0974- 6846 }\end{array}$

authoritative, authoritarian, indulgent, and uninvolved Families. Child Develop. 65, 754-770.

18. Watson D and Clark LA (1997) On traits and temperament: general and specific factors of emotional experience and there relation to five factor model. $J$. Person. 60, 441-467.

19. Atashrouz, Pakdaman, Sh and Asgari A (2008) The relationship between five personality traits and academic achievement. J. Iranian Psychologist. 4 (16), 367-376.

20. Ahadi B (2007) Relationship between personality and marital satisfaction", Contemporary Psychology, 2,2,31-37.

21. Tahmotan K (1998) Relationship between parent's parental styles and student's motivation to progress among male and female guidance school in Fasa preprovince. MA Thesis in Psychol., Shiraz Univ.

22. Razavie A and Khoshbakht F (2005) Study of validity and reliability of children's perception scale from parents in Iran. Modern Educ. Ideas.1(4),23-34.

23. Rozenhan DL and Seligman MEP (2003) Psychological disorder: Psychopathology, translated by Sayed Muhammadi, Tehran, Arasbaran, First Edi.

24. Sepehri S and Mazaheri M (2009) Family communication patterns and personality variables in Children. Evol.Psychol.J.Iranian Psychol.22,141-150

25. Sarmast A (2006) Relationship between parenting styles and stress coping styles. Symp. of Natl. Conf. in Psychology \& Society. Islam. Azad Univ. Roudehen, 22, Tehran, Salavan Press.

26. Sharifi HP and Sharifi N (2004) Research methodologies in behavioral sciences. ${ }^{\text {rd }}$ Edi., Tehran, Sokhan Publ.

27. FathiAshtiani A and DDastani M (2009) Psychological tests: assessing personality and mental health. Tehran, Besat Publ.

28. Feist $J$ and Feist GJ (2002) Theories of personality. Translated by E. Sayed Muhammadi (2005), Tehran, Ravan Publ.

29. Maddahi $M$ and Samadzadeh M (2010) Parenting styles and personality traits. J. Thinking \& Behavior.

30. GarosiFarshi MT (1998) New NEO personality test standardization and study of its features and factorial structure among Iranian universities students. Ph. D. Thesis in Psychol., Teacher Training Univ.

31. Madahi M, Javidi N and Samadzadeh M (2012) The relationship between emotional intelligence and Marital Status in sample of college students. Procedia - Social and Behavioral Sciences

32. Naghashian Z (1979) Relationship between family environment and academic achievement. MA thesis, Shiraz University.

33. Yaghoubkhani Ghasvand M (1993) Relationship between family environment and academic achievement. MA Thesis, Shiraz Univ.

34. Madahi M, Samadzadeh M and Javidi N (2012) The Communication Patterns \& satisfaction in married students. Procedia - Social and Behavioral Sciences. 